\title{
Optimization of Enzymatic Synthesis of Neryl Acetate in a Solvent Free System
}

\author{
Chengjun Jiang1, Guilin Cheng2* \\ ${ }^{1}$ School of Biological and Chemical Engineering, Zhejiang University of Science and Technology, Hangzhou, China \\ ${ }^{2}$ Academy of Chinese Medical Sciences, Zhejiang Chinese Medical University, Hangzhou, China \\ Email: *cheng_guilin@163.com
}

How to cite this paper: Jiang, C.J. and Cheng, G.L. (2020) Optimization of Enzymatic Synthesis of Neryl Acetate in a Solvent Free System. Open Access Library Journal, 7: e6254.

https://doi.org/10.4236/oalib.1106254

Received: March 23, 2020

Accepted: April 6, 2020

Published: April 9, 2020

Copyright $\odot 2020$ by author(s) and Open Access Library Inc.

This work is licensed under the Creative Commons Attribution International License (CC BY 4.0).

http://creativecommons.org/licenses/by/4.0/

\section{(c) (i) Open Access}

\begin{abstract}
Synthesis of valuable flavour and fragrance compounds is one of the intense applications of lipase-catalysed transesterification. This paper demonstrated application of Novozyme 435 to the synthesis of neryl acetate in a solvent free system. Response surface methodology (RSM) complemented by central composite design (CCD) was used to evaluate the effect of various process parameters on reaction conversion. The results showed that $91.6 \%$ conversion of nerol with $100 \%$ selectivity to neryl acetate was obtained under the conditions of 1:12.6 mole ratio of nerol to ethyl acetate, $2.6 \%(\mathrm{w} / \mathrm{w})$ Novozyme 435 at $52.7^{\circ} \mathrm{C}$ for $2 \mathrm{~h}$. From the kinetic study, it was verified that the reaction followed a ternary complex mechanism with inhibition by ethyl acetate. The process was green, clean and useful to the perfume and flavour industries.
\end{abstract}

\section{Subject Areas}

Biological Engineering, Chemical Engineering \& Technology

\section{Keywords}

Nerol, Neryl Acetate, Kinetics, Lipase Catalysis, Transesterification

\section{Introduction}

The world market for flavors is growing steadily with a distinct trend towards "natural" compounds, which are obtained by direct extraction from natural sources in small amounts and too expensive for commercial use [1]. Neryl acetate has a very sweet, floral, orange-blossom and roselike odor. It is initially fresh and pungent, and then a honey-like flavor with a raspberry undertone. Neryl acetate can be prepared by esterification of nerol with acetic acid [2], using sulfuric acid, para-toluene-sulfonic acid or $\mathrm{BF}_{3}$ [3], switchable ionic liquid [4], ca- 
tion-exchange resin [5] as catalysts. However, the presence of acid catalyst in the final product makes it unacceptable by the end-users of flavour and fragrance industries. On the other hand, the enzymatically synthesized flavours and fragrances in a solvent free system are labelled as "natural" and have huge market demand [6] [7] [8]. Furthermore, enzymes give high quality products and also consume lower energy during the reaction. Additionally, the enzyme-catalysed production of flavours and fragrances using solvent free system is preferred over the use of organic solvents [9]. Reactions performed under solvent-free conditions can decrease the production cost as well as the number of downstream steps, thus facilitating its industrial application. Response surface methodology (RSM) is a statistical model approach for empirical modelling which evaluates the effect of individual and interaction effects of the process parameters on the corresponding response value [10]. The present work focused on Novozyme 435 catalysed synthesis of neryl acetate in solvent free conditions (Scheme 1), and response surface methodology (RSM) was used for optimization complemented by central composite design (CCD). The various parameters affecting the synthesis, such as the substrate molar ratio, enzyme loading and the reaction temperature were studied. The bi-substrate kinetic mechanism Ping-Pong Bi-Bi mechanism was tested for the validation of the experimental data.

\section{Material and Methods}

\subsection{Enzymes}

Novozyme 435 (Lipase B from Candida antarctica immobilized on a macroporous acrylic resin, $2728 \mathrm{U} \cdot \mathrm{g}^{-1}$ ) was purchased from NOVOZYMES (China).

\subsection{Chemicals}

Nerol (97\% purity) and ethyl acetate (97\% purity) were used as substrates for the transesterification reaction. All other chemicals were analytical grade obtained from Energy Chem Ltd. (Shanghai, China).

\subsection{Methods}

\subsubsection{Enzymatic Transesterification}

The experimental setup consisted of a glass reactor of $50 \mathrm{~mL}$ capacity equipped with teflon agitator. The entire reactor was assembly dipped in a water bath to maintain the reaction mixture at a desired temperature with an accuracy of<smiles>CCOC(=O)CCCC(C)=CCCC(C)=CCOC(C)=O</smiles>

Scheme 1. Transesterification reaction of nerol with ethyl acetate to produce neryl acetate. 
$\pm 1.0^{\circ} \mathrm{C}$. The transesterification reaction was carried out by changing the known amount of nerol and ethyl acetate in the reactor. The reaction was initiated by adding the Novozym 435 as a catalyst. The reaction mixture was stirred at a certain speed and samples were withdrawn at known time internals.

\subsubsection{Samples Analysis}

The samples were further analyzed by gas chromatography (GC-2014; Shimadzu Corp., Kyoto, Japan) using a capillary column (DB-5HT) fitted with a flame ionization detector (FID). The GC analysis programme was: 1) $100^{\circ} \mathrm{C}, 1 \mathrm{~min}$ hold; 2) ramp rate of $10^{\circ} \mathrm{C} \cdot \mathrm{min}^{-1}$ to $250^{\circ} \mathrm{C}$. The injector and detector temperatures were set at $250^{\circ} \mathrm{C}$. The product was confirmed by gas chromatography-mass spectrometry (GC-MS; QP-2010; Shimadzu Corp., Kyoto, Japan).

\subsubsection{Determination of Initial Rates of Reaction}

Initial rates of transesterification were determined at various reaction conditions, depending on the molar ratio. The molar ratio of nerol to ethyl acetate varied from 5:1 to 1:5 in integral successions. The temperature was maintained at $50^{\circ} \mathrm{C}$ with $1 \%(\mathrm{w} / \mathrm{w})$ enzyme loading. Reactions were carried out for $120 \mathrm{~min}$ at $400 \mathrm{rpm}$. Aliquots of the reaction mixture were taken sequentially and analyzed by GC as discussed above. Conversion data for $<10 \%$ conversion was used to determine initial reaction rates by plotting conversion versus time profiles. Experiments were carried out in a solvent free system by keeping the concentration of one substrate constant in either a specific or random manner, to form a complex through varying concentration of the other and vice versa.

\subsubsection{Experiment Design}

The lipase catalyzed synthesis of flavour and fragrance compounds involved interactions among several variables, therefore traditional methods were inefficient for optimization of the reaction. Single factor method, such as the molar ratio, enzyme loading and temperature, was found as significant parameter affecting transesterification conversion of geraniol-isomers of nerol [11]. Response surface methodology was further selected here. Design Expert 8.0.6.1 software was used for designing the experiments and analysis of the data. According to a central composite design (CCD), 20 experiments were performed in the study to find the optimum combination and effect of parameters on the enzymatic synthesis of neryl acetate (Table 1). The variables and their levels selected for the

Table 1. Variables and their levels employed in the central composite design method for optimal neryl acetate production.

\begin{tabular}{cccc}
\hline Variable & \multicolumn{3}{c}{ Levels } \\
\hline Molar ratio (nerol:ethyl acetate) & -1 & 0 & 1 \\
Enzyme loading $(\% \mathrm{w} / \mathrm{w})$ & $1: 5$ & $1: 10$ & $1: 15$ \\
Temperature $\left({ }^{\circ} \mathrm{C}\right)$ & 1 & 2 & 3 \\
\hline
\end{tabular}


study of neryl acetate synthesis were the molar ratio of nerol to ethyl acetate (1:5 to $1: 15)$, enzyme dosage ( 1 to $3 \% \mathrm{w} / \mathrm{w})$ and reaction temperature $\left(40^{\circ} \mathrm{C}\right.$ to $\left.60^{\circ} \mathrm{C}\right)$. All the experiments were carried out in random order.

\subsubsection{Data Analysis}

The experimental data were analyzed and interpreted using Design Expert Software (Version 8.0.6) from Stat-Ease Inc. (USA). The three main analytical steps were the analysis of variance (ANOVA), regression analysis and the plotting of response surface. Experimental data from the CCD were analyzed using regression analysis and fitted to a second order polynomial model in order to identify all possible interactions of selected factors with a response function as:

$$
Y=b_{0}+\sum_{i=1}^{4} b_{i} x_{i}+\sum_{i=1}^{4} b_{i i} x_{i}^{2}+\sum_{i=1}^{3} \sum_{j=i+1}^{4} b_{i j} x_{i j}
$$

where $Y$ is percentage of conversion; $b_{0}, b_{\dot{p}} b_{i \dot{ }}$ and $b_{i j}$ are constant coefficients; and $x_{i}$ is the uncoded independent variable.

\section{Results and Discussion}

\subsection{Production Confirm}

The enzymatic synthesis of neryl acetate product was confirmed by GC-MS analysis (Figure 1).

It was obvious from GC-MS that neryl acetate was the main product. The retention time of nerol and neryl acetate was 6.335 and $8.097 \mathrm{~min}$, respectively.

\subsection{Effect of Speed of Agitation}

Solid-liquid mass transfer resistance around the particle, caused by pathway blockage or by the reduced solubility of reactants and products, might influence the performance of the enzyme [12] [13].

Therefore, the external mass transfer effects and intra-particle diffusion limitations were investigated using the strategy of changing one parameter at a time. The effect of agitation speed on conversion and the initial rate was studied over the range of $200-500 \mathrm{rpm}$. The conversion and initial rate increased with agitation speeds from 200 to $400 \mathrm{rpm}$. Figure 2 showed that there was an insignificant increase in conversion above $400 \mathrm{rpm}$. The conversion and reaction rate were no longer limited by mass transfer resistance at or beyond $400 \mathrm{rpm}$.

\subsection{Model Fitting and Analysis of Variance}

For the optimization of enzymatic synthesis of neryl acetate in a solvent free system, we used the CCD (factorial design) to analyze the following variables: reaction temperature, molar ratio of nerol to ethyl acetate and enzyme loading (Table 2).

The ANOVA done after fitting the data to the various models (linear, two factorial, quadratic and cubic) showed that the transesterification reaction carried out for the formation of neryl acetate was best described by a quadratic 

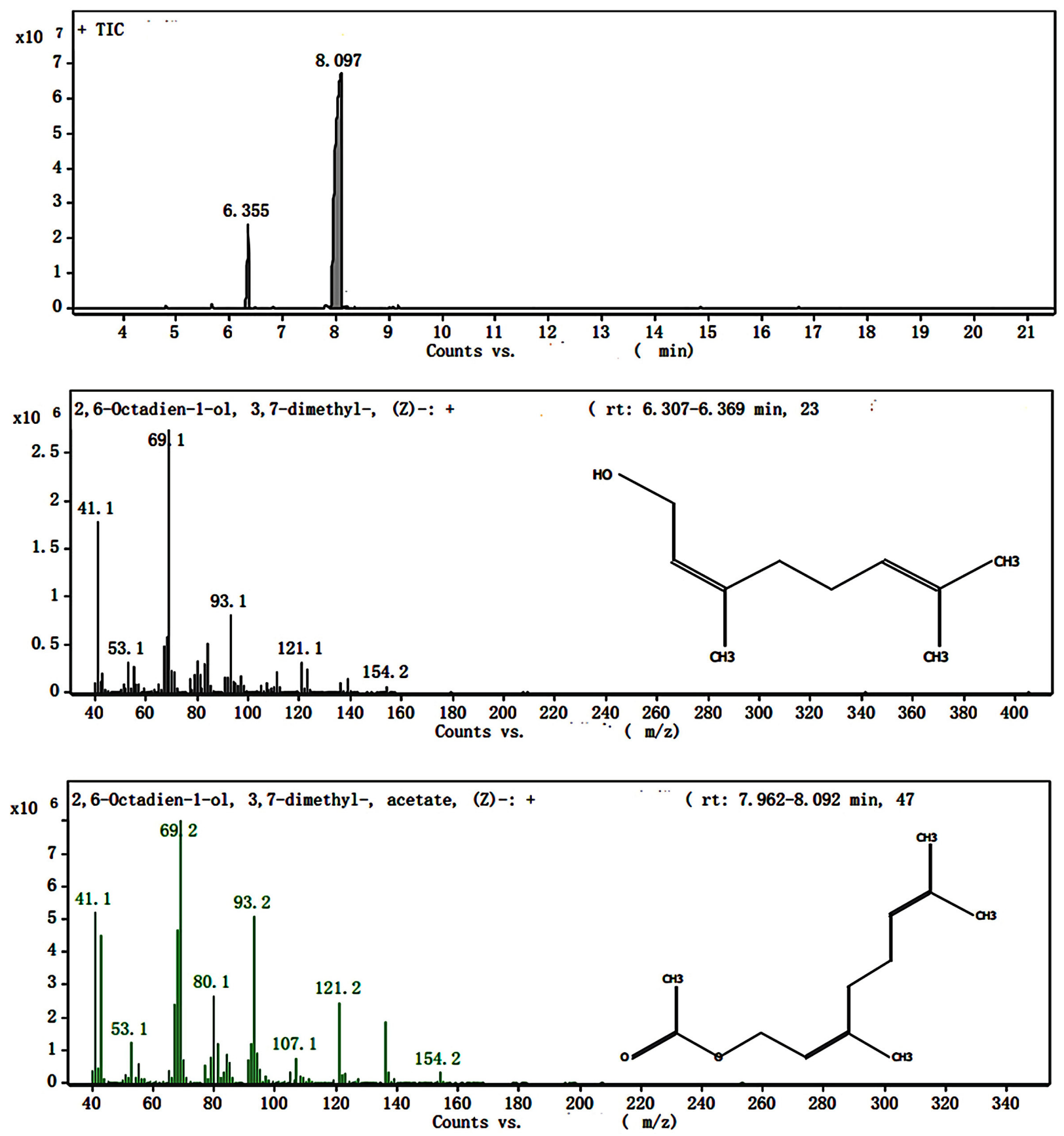

Figure 1. The illustrative GC-MS of neryl acetate product.

model equation. The equation of the model obtained based on the coded values was as follows:

$$
\begin{gathered}
Y=90.12+3.11 A+1.74 B+1.22 C-0.96 A B \\
-0.56 A C+0.21 B C-2.28 A^{2}-1.08 B^{2}-1.94 C^{2}
\end{gathered}
$$

Here, $Y=$ Conversion\%, $A=$ Molar ratio, $B=$ Enzyme loading and $C=$ Temperature. The ANOVA for the model was as shown in Table 3. The acceptability and significance of the model are generally checked by model $\mathrm{F}$ values, $\mathrm{p}$-values and adequate precision. According to Table 3, the F-value (23.16) with 
Table 2. Composition of the various runs of the CCD (in terms of coded factors), actual, and predicted responses for synthesis of neryl acetate.

\begin{tabular}{cccccc}
\hline Run & Molar ratio & Enzyme loading (\%) & Temperature $\left({ }^{\circ} \mathrm{C}\right)$ & $\begin{array}{c}\text { Actual } \\
\text { Conversion }(\%)\end{array}$ & $\begin{array}{c}\text { Predicted } \\
\text { Conversion }(\%)\end{array}$ \\
\hline 1 & $1(1: 15)$ & $-1(1)$ & $-1(40)$ & 86.7 & 86.71 \\
2 & $-1(1: 5)$ & $-1(1)$ & $1(60)$ & 81.2 & 80.57 \\
3 & $1(1: 15)$ & $1(3)$ & $1(60)$ & 89.0 & 89.58 \\
4 & $-1.68(1: 1.6)$ & $0(2)$ & $0(50)$ & 79.0 & 78.43 \\
5 & $1.68(1: 18.4)$ & $0(2)$ & $0(50)$ & 90.2 & 88.91 \\
6 & $1(1: 15)$ & $1(3)$ & $-1(40)$ & 85.9 & 87.84 \\
7 & $0(1: 10)$ & $0(2)$ & $0(50)$ & 90.0 & 88.91 \\
8 & $0(1: 10)$ & $0(2)$ & $0(50)$ & 90.1 & 90.12 \\
9 & $0(1: 10)$ & $0(2)$ & $1.68(66.8)$ & 87.2 & 86.67 \\
10 & $0(1: 10)$ & $-1.68(0.32)$ & $0(50)$ & 84.0 & 84.15 \\
11 & $-1(1: 5)$ & $1(3)$ & $1(60)$ & 85.1 & 86.40 \\
12 & $-1(1: 5)$ & $1(3)$ & $-1(40)$ & 81.8 & 82.41 \\
13 & $-1(1: 5)$ & $-1(1)$ & $-1(40)$ & 76.7 & 77.43 \\
14 & $1(1: 15)$ & $-1(1)$ & $1(60)$ & 86.9 & 87.60 \\
15 & $0(1: 10)$ & $1.68(3.68)$ & $0(50)$ & 92.0 & 90.00 \\
16 & $0(1: 10)$ & $0(2)$ & $0(50)$ & 89.9 & 90.12 \\
17 & $0(1: 10)$ & $0(2)$ & $0(50)$ & 90.2 & 90.12 \\
18 & $0(1: 10)$ & $0(2)$ & $-1.68(33.2)$ & 83.9 & 82.57 \\
19 & $0(1: 10)$ & $0(2)$ & $0(50)$ & 90.3 & 90.12 \\
20 & $0(1: 10)$ & $0(2)$ & $0(50)$ & 89.9 & 90.12 \\
\hline & & & & & \\
\hline
\end{tabular}

Table 3. ANOVA test for percentage conversion of nerol.

\begin{tabular}{|c|c|c|c|c|c|c|}
\hline Source & Sum of Squares & $\mathrm{df}$ & Mean Square & F Value & Prob $>$ F & \\
\hline Model & 329.34 & 9 & 36.59 & 23.16 & $<0.0001$ & significant \\
\hline$A$ & 132.48 & 1 & 132.48 & 83.84 & $<0.0001$ & \\
\hline$B$ & 41.32 & 1 & 41.32 & 26.15 & 0.0005 & \\
\hline C & 20.30 & 1 & 20.30 & 12.85 & 0.0050 & \\
\hline$A B$ & 7.41 & 1 & 7.41 & 4.69 & 0.0556 & \\
\hline$A C$ & 2.53 & 1 & 2.53 & 1.60 & 0.2343 & \\
\hline$B C$ & 0.36 & 1 & 0.36 & 0.23 & 0.6428 & \\
\hline$A^{2}$ & 74.89 & 1 & 74.89 & 47.39 & $<0.0001$ & \\
\hline$B^{2}$ & 16.73 & 1 & 16.73 & 10.59 & 0.0087 & \\
\hline$C^{2}$ & 54.45 & 1 & 54.45 & 34.46 & 0.0002 & \\
\hline Residual & 15.80 & 10 & 1.58 & & & \\
\hline Lack of fit & 15.67 & 5 & 3.13 & 117.52 & $<0.0001$ & significant \\
\hline Pure Error & 0.13 & 5 & 0.027 & & & \\
\hline Cor Total & 345.14 & 19 & & & & \\
\hline
\end{tabular}




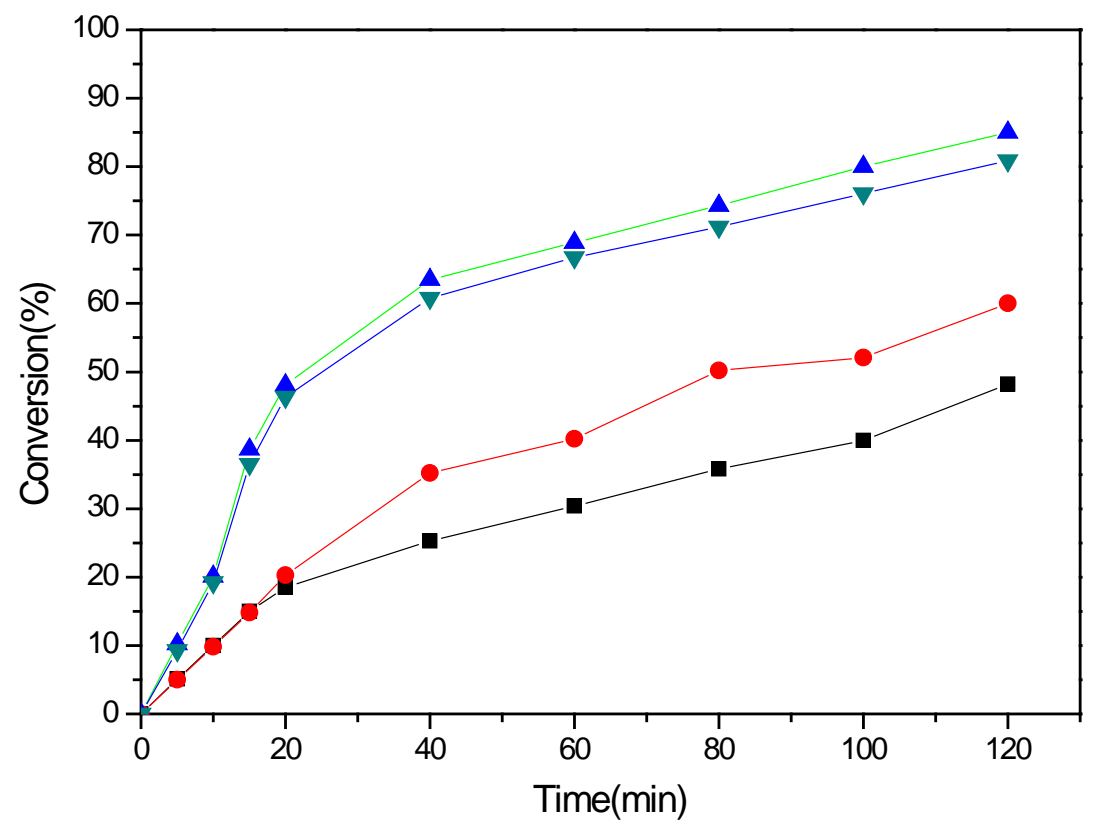

Figure 2. Effect of speed of agitation. Reaction conditions: $20 \mathrm{mmol}$ nerol geraniol; 140 mmol ethyl acetate; total volume, $17 \mathrm{ml}$; temperature, $60^{\circ} \mathrm{C}$; catalyst, $200 \mathrm{mg}$. Speed of agitation: $\boldsymbol{\square}, 200 \mathrm{rpm} ; 0,300 \mathrm{rpm} ; \boldsymbol{\nabla}, 400 \mathrm{rpm} ; \boldsymbol{\Delta}, 500 \mathrm{rpm}$.

a p-value less than 0.0001 implied that the model was significant. There was only a $0.01 \%$ chance that a "Model F-Value" this large could occur due to noise. Values of "Prob > F" less than 0.0500 indicated model terms were significant. The coefficient of determination $\left(R^{2}\right)$ turned out to be 0.9542 , which showed the suitability of the model to represent the relationship between reaction parameters. The value of $\mathrm{R}^{2}$ adj was 0.9130 indicating the significance of the model. Enough accuracy was available to measure the signal-to-noise ratio (SNR) and should preferably be greater than 4 . In the present work, the value of SNR was 14.272, which confirmed that the model could be successfully used for the enzymatic synthesis of neryl acetate.

Table 3 illustrated the values of the model terms. Out of them, the terms $A, B$, $C, A B, A^{2}, B^{2}$ and $C^{2}$ were considered important. Values greater than 0.10 indicated that the model terms were not significant. Figure 3 showed the normal probability plot which described the relationship between actual values of conversion rate and those predicted by the model.

\subsection{Effect of Parameters and Optimum Conditions}

According to ANOVA, the relationships between temperature and other reaction parameters were studied by a series of contour plots which were generated from the predicted model. The plots efficiently indicated the effect of reaction parameters on the synthesis of the ester. Figure 4 depicted the combined effect of enzyme loading and molar ratio on the conversion rate at a constant temperature of $50^{\circ} \mathrm{C}, 400 \mathrm{rpm}$ and $120 \mathrm{~min}$ reaction time. The lower conversion was observed when the enzyme loading was $1.0 \%$ and the molar ratio was $1: 5$. The 
Design-Expert?Software

Conversion

Color points by value of Conversion:

92

76

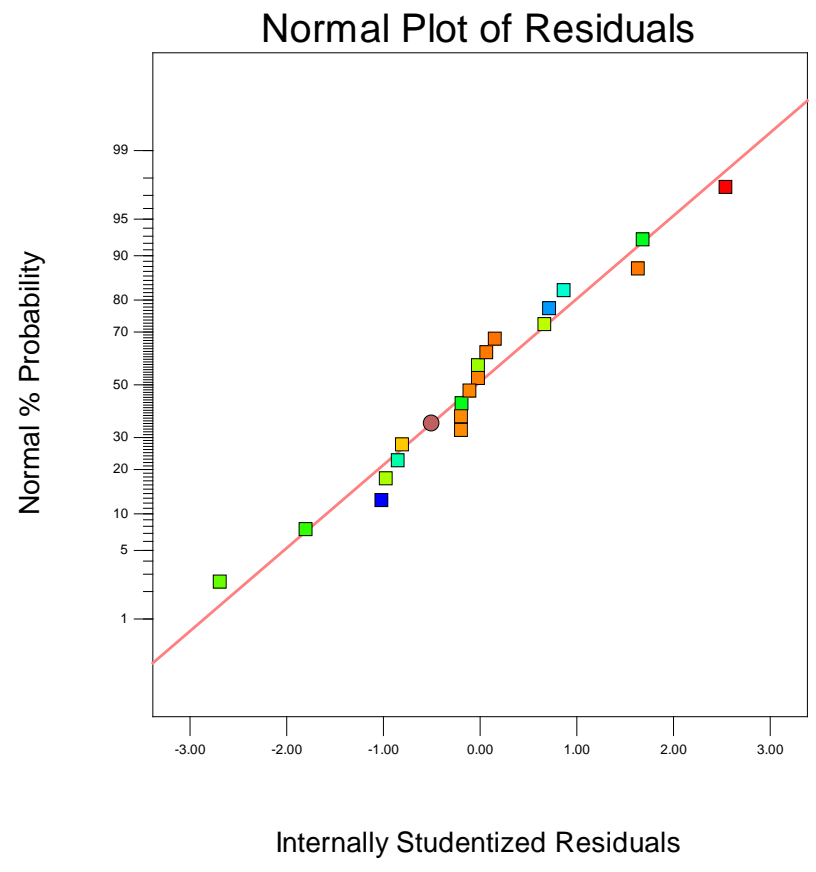

Figure 3. Normal probability plot of studentized residuals for the purpose of checking the normality of the residues.

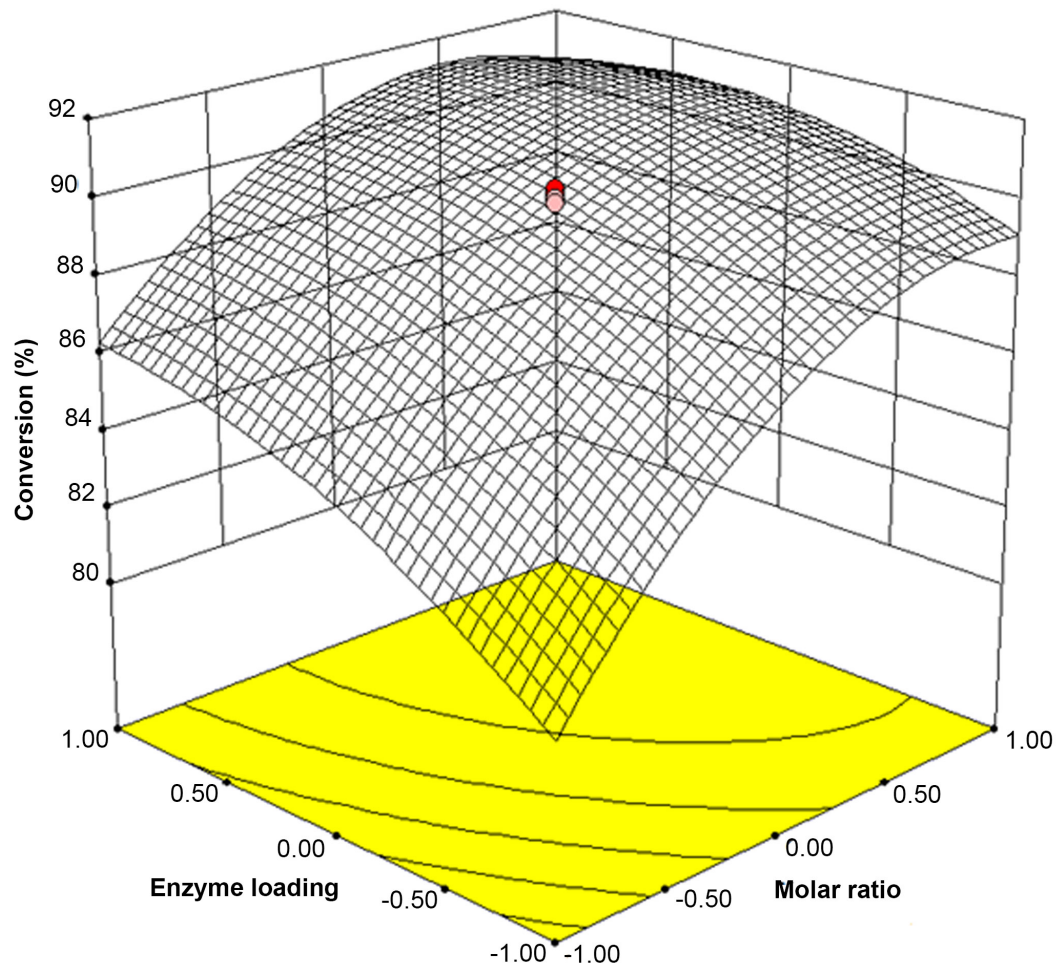

Figure 4. Contour plot showing the relationship between the enzyme lading, molar ratio and the conversion.

conversion was increased with the enzyme loading from $1.0 \%$ to $3.0 \%$. However, further increase of enzyme loading would reduce the conversion rate of nerol to 
ethyl acetate. Ethyl acetate had been reported to be competitive inhibitor of lipases, so an increase in ethyl acetate amount would inhibit the enzyme activity and decrease the conversion rate of nerol [11].

Figure 5 showed the combined effect of temperature and molar ratio on the conversion rate in $120 \mathrm{~min}$. An increase of ethyl acetate amount (the ratio of nerol to ethyl acetate $=1: 15$ ) improved the conversion of nerol. Thus, a higher molar ratio of ethyl acetate to nerol was chosen so that the alcohol could act as solvent for the nerol. Further increase of the amount of ethyl acetate would reduce the conversion rate at high temperature. This indicated that ethyl acetate was a terminal inhibitor of the enzyme and its effect could increase at high temperature.

Figure 6 described the effect of temperature, enzyme loading and their mutual interaction on conversion of nerol. It is well known that the collisions between enzyme and substrate molecules will enhance with the increase of temperature, resulting in higher reaction rate and conversion. It was observed that the conversion increased with enzyme loading from $1 \%$ to $3 \%(w / w)$ due to $n$ increase in the number of active sites. The highest on conversion could be attained when the enzyme loading was taken as $2 \%$ at temperature of $50^{\circ} \mathrm{C}$. The reaction rate decreased with an increase of temperature from $50^{\circ} \mathrm{C}$ to $60^{\circ} \mathrm{C}$ due to destruction of enzymatic tertiary structure and denaturation at higher temperature.

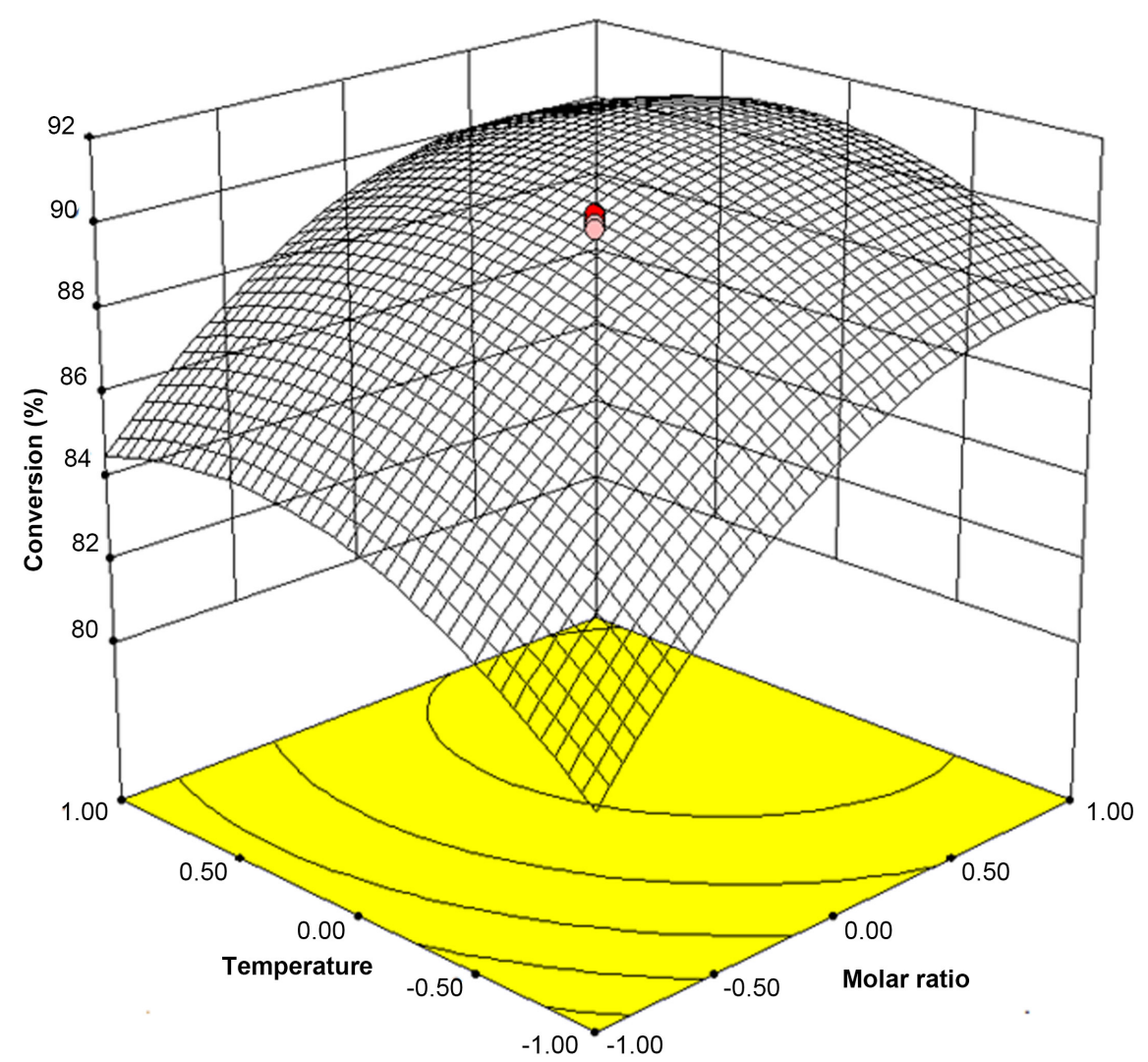

Figure 5. Contour plot showing the relationship between the temperature, molar ratio and the conversion. 


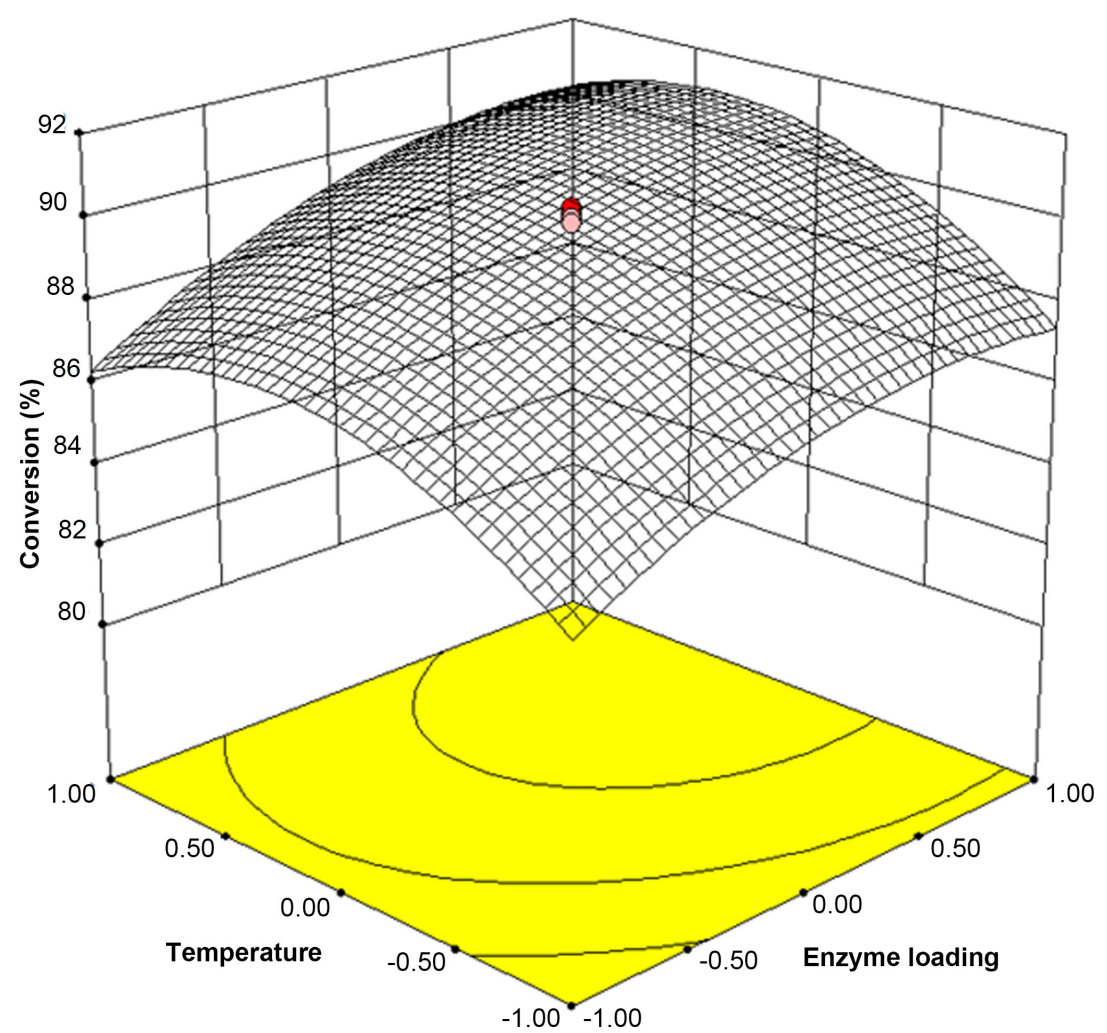

Figure 6. Contour plot showing the relationship between the temperature, enzyme lading and the $\%$ conversion.

\subsection{Optimum Conditions and Validation of Model}

The maximum conversion predicted by design expert software was $91.62 \%$ at the conditions of $52.7^{\circ} \mathrm{C}, 2.6 \%$ enzyme amount and 1:12.6 molar ratio of nerol to ethyl acetate during $120 \mathrm{~min}$ reaction time. The conversion of $91.62 \%$ was obtained when the experiment was conducted at similar conditions. In order to validate the predictions made by the model, experiments were conducted for three times under the optimal process conditions given by the model. Under the experimental conditions, the conversion rate was about $90.54 \%$, very close to the maximum predicted value of $90.99 \%$, which illustrated that model Equation (2) could predict the conversion rate very appropriately (Table 4).

\subsection{Kinetic Analysis of the Process Based on Initial Rate Measurement}

The kinetics of geranyl acetate synthesis was studied from the initial rates of reaction. The initial rate of reaction was improved by increasing the concentration of nerol $[A]$. While the concentration of ethyl acetate $[B]$ was increased from 1 to $10 \mathrm{~mol} / \mathrm{L}$, the reaction rate was observed to decrease with the same concentration of nerol, which indicated that ethyl acetate had a certain inhibitory effect on enzyme. It seemed that higher concentrations of ethyl acetate could lead to a complex of inhibiting enzyme. Reaction mechanism could be shown as follows: 
Table 4. Solution to the range of input parameters and responses with desirability for enzymatic synthesis of ethyl hexanoate.

\begin{tabular}{ccccc}
\hline Solutions number & Molar ratio & Enzyme loading (\%) & Temperature $\left({ }^{\circ} \mathrm{C}\right)$ & Conversion (\%) \\
\hline 1 & 12.6 & 2.6 & 52.7 & 91.6 \\
2 & 12.6 & 2.6 & 52.7 & 91.7 \\
3 & 12.6 & 2.6 & 52.7 & 91.6 \\
\hline
\end{tabular}

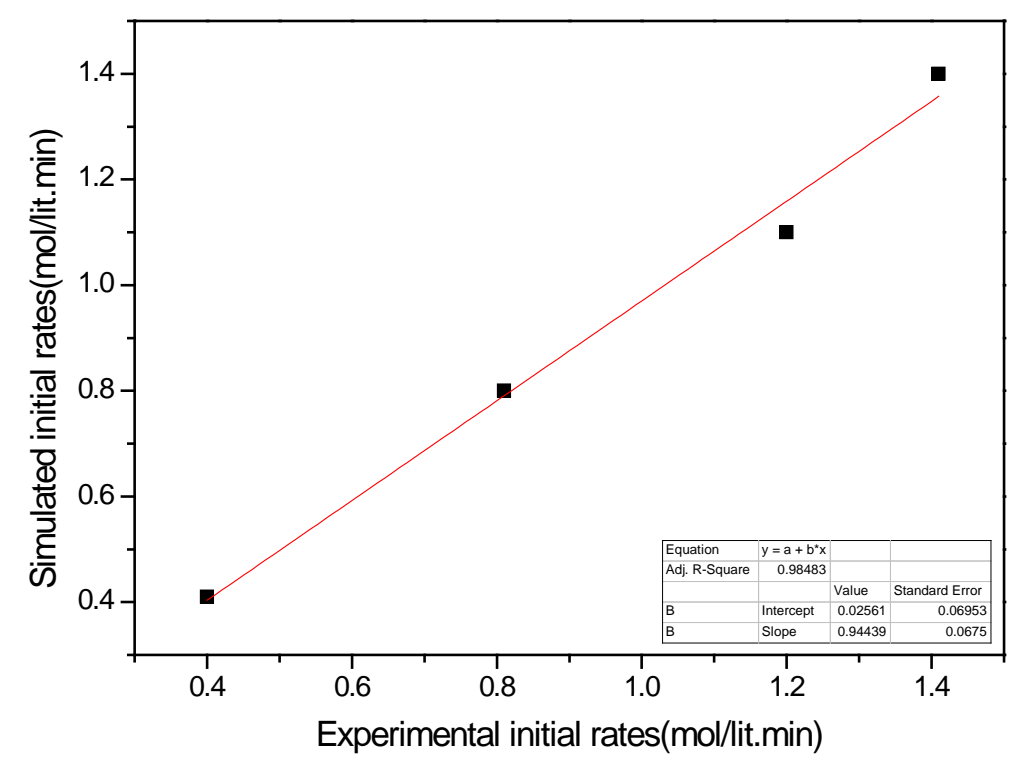

Figure 7. Parity plot for experimental and simulated initial rates.

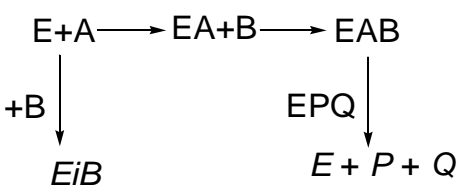

To determine the kinetic parameters of the transesterification, several experiments were carried out by varying the ratio of nerol to ethyl acetate from 1:1 to 1:10. According to Ping-Pong Bi-Bi mechanism, two substrates nerol $[A]$ and ethyl acetate $[B]$ were initially bound to the immobilized lipase $[E]$ to form a complex $[\mathrm{EAB}]$. The ternary complex was then isomerized to form another complex [EPQ], which released product $[P]$ and ethanol $[Q]$. Kinetic parameters were determined graphically. The general rate equation for the Ping-Pong Bi-Bi mechanism [14] could be proposed as follows:

$$
v_{0}=\frac{V_{\max }[A][B]}{[A][B]+K_{M A}[B]\left(1+[B] / K_{i B}\right)+K_{M B}[A]\left(1+[A] / K_{i A}\right)}
$$

The constants in Equation (2) were calculated in polymath 6.0 with nonlinear regression mode to get: $V_{\max }=23.5 \mathrm{~mol} \cdot \mathrm{L}^{-1} \cdot \mathrm{min}^{-1}$; Michaelis constant for geraniol $K_{M A}=2.7 \mathrm{~mol} \cdot \mathrm{L}^{-1}$; Michaelis constant for ethyl acetate $K_{M B}=0.02 \mathrm{~mol} \cdot \mathrm{L}^{-1}$; inhibition constant by ethyl acetate $K_{i B}=51.5 \mathrm{~mol} \cdot \mathrm{L}^{-1}$; and dissociation constant for the enzyme-nerol complex $K_{i A}=0.2 \mathrm{~mol} \cdot \mathrm{L}^{-1}$. The straight line (Figure 7) 
passing through the origin in the parity plot confirmed that the model was valid.

\section{Conclusions}

Neryl acetate synthesis using immobilized Candida antarctica lipase (Novozyme 435) was successfully performed and modelling of the synthesis was done by central composite design and response surface methodology. The $\mathrm{R}^{2}$ obtained after the model fitting was 0.9542 and ANOVA indicated that the model had satisfactorily reflected and explained the real relationship between the reaction parameters. Compared with the single factor method, the statistical optimization method gave $2 \%-3 \%$ increase in conversion. The molar ratio, enzyme loading and temperature illustrated a significant effect on the esterification reaction.

The esterification reaction seemed to follow a Ping-Pong Bi-Bi mechanism with competitive inhibition by nerol and ethyl acetate. Overall, the data obtained here will be further useful for future up-scaling of the enzyme catalysis of honey-like flavor.

\section{Acknowledgements}

The financial assistance provided by Zhejiang Province Public Welfare Research Project (LGJ20B060001), Zhejiang University of Traditional Chinese Medicine Research Fund Project (2019ZG48), China National Natural Science Foundation (21602206) is acknowledged.

\section{Conflicts of Interest}

The authors declare no conflicts of interest regarding the publication of this paper.

\section{References}

[1] Serra, S., Fuganti, C. and Brenna, E. (2005) Biocatalytic Preparation of Natural Flavours and Fragrances. Trends in Biotechnology, 23, 193-198. https://doi.org/10.1016/j.tibtech.2005.02.003

[2] Gupta, P., Taneja, S.C., Shah, B.A., Sethi, V.K. and Qazi, G.N. (2007) Lipase-Catalyzed Separation of Geometrical Isomers: Geraniol-Nerol. Chemistry Letters, 36, 1110-1111. https://doi.org/10.1246/cl.2007.1110

[3] Hoydonckx, H.E., De Vos, D.E., Chavan, S.A. and Jacobs, P.A. (2004) Esterification and Transesterification of Renewable Chemicals. Topics in Catalysis, 27, 83-96. https://doi.org/10.1023/B:TOCA.0000013543.96438.1a

[4] Lozano, P., Bernal, J.M. and Navarro, A. (2012) A Clean Enzymatic Process for Producing Flavour Esters by Direct Esterification in Switchable Ionic Liquid/Solid Phases. Green Chemistry, 14, 3026-3033. https://doi.org/10.1039/c2gc36081k

[5] Yadav, G.D. and Rahuman, M.S.M.M. (2002) Cation-Exchange Resin-Catalysed Acylations and Esterifications in Fine Chemical and Perfumery Industries. Organic Process Research \& Development, 6, 706-713. https://doi.org/10.1021/op0255229

[6] Corradini, M.C.C., Gomes, R.A.B., Luiz, J.H.H. and Mendes, A.A. (2016) Optimization of Enzymatic Synthesis of n-Propyl Acetate (Fruit Flavor Ester)-Effect of the Support on the Properties of Biocatalysts. Chemical Engineering Communications, 
203, 1432-1442. https://doi.org/10.1080/00986445.2016.1201658

[7] Serra, S., Fuganti, C. and Brenna, E. (2005) Biocatalytic Preparation of Natural Flavours and Fragrances. Trends in Biotechnology, 23, 193-198.

https://doi.org/10.1016/j.tibtech.2005.02.003

[8] Ferreira-Dias, S., Sandoval, G., Plou, F. and Valero, F. (2013) The Potential Use of Lipases in the Production of Fatty Acid Derivatives for the Food and Nutraceutical Industries. Electronic Journal of Biotechnology, 16, 1-34.

https://doi.org/10.2225/vol16-issue3-fulltext-5

[9] Dhake, K.P., Thakare, D.D. and Bhanage, B.M. (2013) Lipase: A Potential Biocatalyst for the Synthesis of Valuable Flavour and Fragrance Ester Compounds. Flavour and Fragrance Journal, 28, 71-83. https://doi.org/10.1002/ffj.3140

[10] Yolmeh, M. and Jafari, S.M. (2017) Applications of Response Surface Methodology in the Food Industry Processes. Food and Bioprocess Technology, 10, 413-433. https://doi.org/10.1007/s11947-016-1855-2

[11] Bhavsar, K.V. and Yadav, G.D. (2019) Synthesis of Geranyl Acetate by Transesterification of Geraniol with Ethyl Acetate over Candida Antarctica Lipase as Catalyst in Solvent-Free System. Flavour and Fragrance Journal, 34, 288-293.

https://doi.org/10.1002/ffj.3502

[12] Yadav, G.D. and Trivedi, A.H. (2003) Kinetic Modeling of Immobilized-Lipase Catalyzed Transesterification of Noctanol with Vinyl Acetate in Nonaqueous Media. Enzyme and Microbial Technology, 32, 783-789. https://doi.org/10.1016/S0141-0229(03)00064-4

[13] Laane, C., Boeren, S., Vos, K. and Veeger, C. (2009) Rules for Optimization of Biocatalysis in Organic Solvents. Biotechnology \& Bioengineering, 102, 1-8. https://doi.org/10.1002/bit.22209

[14] Yadav, G.D. and Devi, K.M. (2004) Immobilized Lipase-Catalysed Esterification and Transesterification Reactions in Non-Aqueous Media for the Synthesis of Tetrahydrofurfuryl Butyrate: Comparison and Kinetic Modeling. Chemical Engineering Science, 59, 373-383. https://doi.org/10.1016/j.ces.2003.09.034 